34 The Air Force Weather Agency (AFWA) - NASA blended snow-cover product, called

\section{Improving the Accuracy of the AFWA-NASA (ANSA) Blended Snow-Cover Product over the Lower Great Lakes Region}

\author{
Dorothy K. Hall ${ }^{1}$ \\ James L. Foster ${ }^{2}$ \\ Sujay Kumar ${ }^{2,3}$ \\ Janet Y.L. Chien ${ }^{1,4}$ \\ George A. Riggs ${ }^{1,5}$ \\ ${ }^{1}$ Cryospheric Sciences Laboratory \\ NASA Goddard Space Flight Center \\ Greenbelt, MD 20771 \\ dorothy.k.hall@nasa.gov \\ ${ }^{2}$ Hydrological Sciences Laboratory \\ NASA Goddard Space Flight Center \\ Greenbelt, MD 20771 \\ james.I.foster@nasa.gov \\ ${ }^{3}$ SAIC, Inc., 1710 SAIC Drive \\ McLean, VA 22102 \\ sujay.v.kumar@nasa.gov \\ ${ }^{4}$ Consultant \\ and \\ ${ }^{5}$ SSAI, Lanham, MD 20706 \\ george.a.riggs@nasa.gov
}

\section{Abstract}

ANSA, utilizes Earth Observing System standard snow products from the Moderate-

Resolution Imaging Spectroradiometer (MODIS) and the Advanced Microwave

Scanning Radiometer for EOS (AMSR-E) to map daily snow cover and snow-water equivalent (SWE) globally. We have compared ANSA-derived SWE with SWE values calculated from snow depths reported at $\sim 1500$ National Climatic Data Center (NCDC) 
40 co-op stations in the Lower Great Lakes Basin. Compared to station data, the ANSA

41 significantly underestimates SWE in densely-forested areas. We use two methods to

42 remove some of the bias observed in forested areas to reduce the root-mean-square

43 error (RMSE) between the ANSA- and station-derived SWE. First, we calculated a 5-

44 year mean ANSA-derived SWE for the winters of 2005-06 through 2009-10, and

45 developed a five-year mean bias-corrected SWE map for each month. For most of the

46 months studied during the five-year period, the 5-year bias correction improved the

47 agreement between the ANSA-derived and station-derived SWE. However, anomalous

48 months such as when there was very little snow on the ground compared to the 5-year

49 mean, or months in which the snow was much greater than the 5-year mean, showed

50 poorer results (as expected). We also used a 7-day running mean (7DRM) bias

51 correction method using days just prior to the day in question to correct the ANSA data.

52 This method was more effective in reducing the RMSE between the ANSA- and co-op-

53 derived SWE values, and in capturing the effects of anomalous snow conditions.

55 Introduction

57 Significant reductions in the extent of spring snow cover in the Northern Hemisphere

58 have been measured during the satellite era (Brown, 2000; Brown et al., 2010) and over

59 the past 90 years, including about 50 years of the pre-satellite era (Brown and

60 Robinson, 2011). Accelerated warming is most likely responsible for the observed

61 accelerated decrease in Northern Hemisphere spring snow cover in recent years 
62 (Brown and Robinson, 2011). It is important to monitor snow depth and snow-water

63 equivalent (SWE) as well as snow extent.

64

65 Consistent and reliable snow maps are needed by the climate-modeling community to

66 to improve the predictive capabilities of the models, and to validate their performance.

67 Several global snow maps are in widespread use (e.g., Robinson et al., 1993; Ramsay,

68 1998; Hall et al., 2002; Kelly et al., 2004; Frei et al., submitted). Most satellite-derived

69 global snow maps have relied on utilization of data from one primary satellite, though

70 the NOAA National Ice Center utilizes multiple satellite datasets as well as station data

71 to construct daily maps (Helfrich et al., 2007).

73 The Great Lakes Basin is a challenging study area for mapping snow using satellite

74 data for several reasons. Persistent cloud cover is a serious issue when observing

75 snow using sensors operating in the visible-near-infrared (VNIR) wavelengths. And

76 passive-microwave algorithms have limitations when mapping the shallow often

77 ephemeral snow in this region as well as the wet snow - daytime temperatures are

78 typically above $0^{\circ} \mathrm{C}$ in the lower Great Lakes area. Moreover, the large footprint size of

79 passive-microwave sensors means that small scale lake-effect snow events may be

80 missed.

82 A blended snow-cover product has been developed jointly by the U.S. Air Force

83 Weather Agency (AFWA) and the Hydrospheric and Biospheric Sciences Laboratory at

84 NASA / Goddard Space Flight Center. A detailed description of the product, derived 
85 from the AFWA - NASA Snow Algorithm (ANSA) may be found in Foster et al. (2011).

86 The objective of the present work is to characterize the accuracy of the SWE derived

87 from the ANSA snow maps in a region within the Lower Great Lakes Basin for the

88 winters of 2005-06 through 2009-10 using meteorological-station data. We also

89 describe methods to improve the accuracy of the ANSA-derived SWE by reducing the

90 bias in the ANSA measurements.

\section{Study area}

95 The Great Lakes system (Figure 1) is the largest surface freshwater system on the

96 planet. It drains an area of approximately $1,600,000 \mathrm{~km}^{2}$ and stretches from northern

97 Minnesota / western Ontario to the Gulf of St. Lawrence. The mean annual flow, as

98 measured at the mouth of the St. Lawrence River, is approximately $12,600 \mathrm{~m}^{3} / \mathrm{s} / \mathrm{km}$.

99 Snow cover is prevalent during winter, and snowfall averages more than $80 \mathrm{~cm}$ in

100 southern locations and more than $250 \mathrm{~cm}$ at a few locations in the lee of Lake Superior

101 and Lake Ontario and at the highest elevations. Basin relief is rather low -- on the order

102 of hundreds of meters. Vegetation consists of transitional mixed forests, northern

103 hardwoods, and Great Lakes spruce and pine forest. 

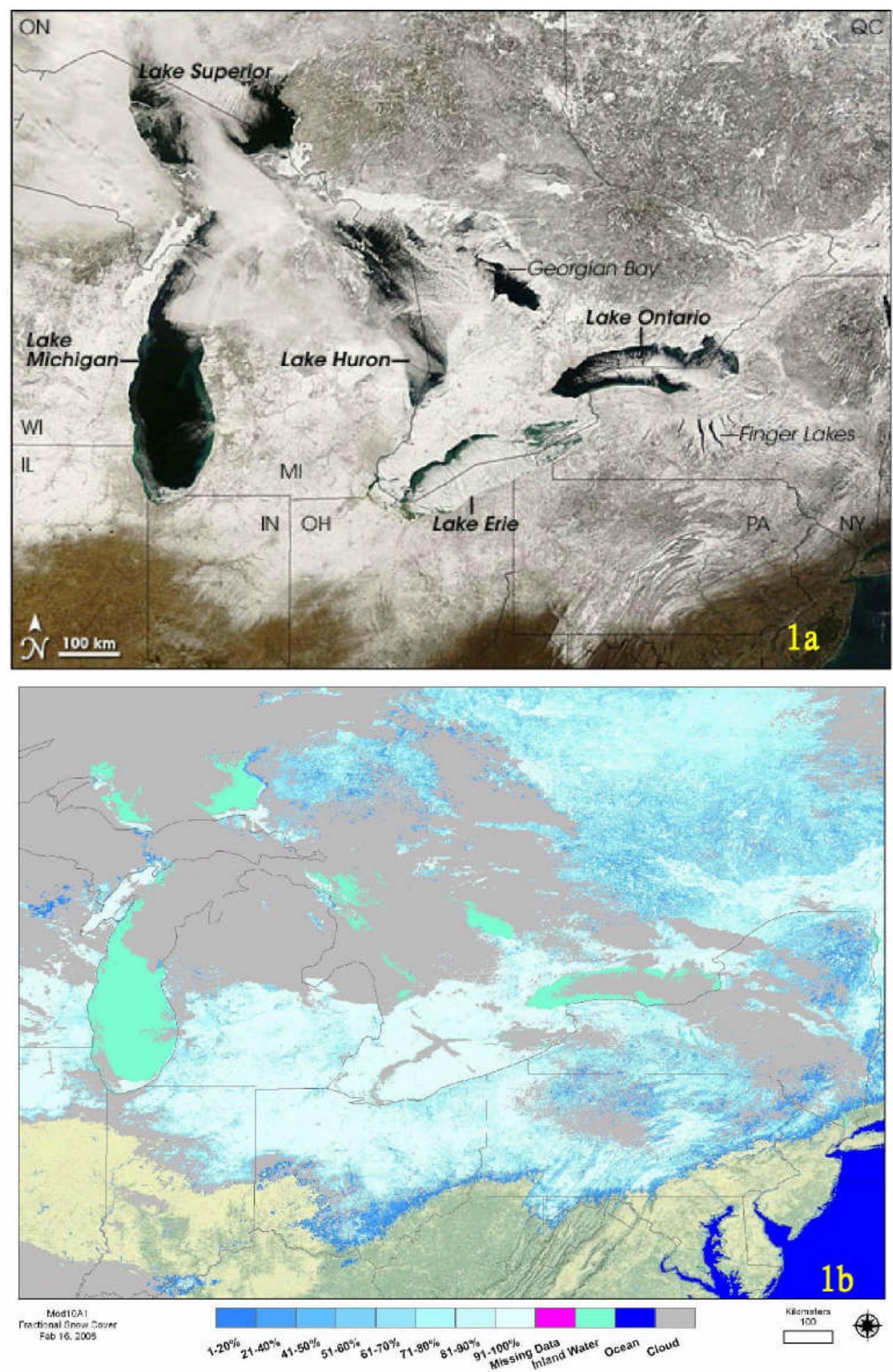
108 The Great Lakes Basin is subject to lake-effect snowfall, particularly elevated areas in

109 the lee of the Great Lakes. Lake-effect snowfall is produced when cold winds move

110 across long expanses of relatively-warmer lake water; the warmer water provides

111 energy and a source of water vapor. Snow deposited on the leeward shores can

112 accumulate to significant depths in relatively short periods -- $0.5 \mathrm{~m}$ or more in 24 hours.

113 Though the heaviest accumulations typically occur within $80 \mathrm{~km}$ of the lakes, on

114 occasion lake-effect snow may fall $320 \mathrm{~km}$ downstream. For example, the highlands of

115 West Virginia receive most non-storm snowfall from lake-effect snows from Lake Erie.

118 Air Force - NASA Snow Algorithm (ANSA) snow product

120 An example of the ANSA snow product is provided in Figure 2. The product utilizes the 121 Moderate-Resolution Imaging Spectroradiometer (MODIS) standard snow-cover maps 122 (Hall and Riggs, 2007) and the Advanced Microwave Scanning Radiometer for EOS 123 (AMSR-E), a passive-microwave instrument, standard snow-water equivalent (SWE) 124 maps (Kelly et al., 2004; Kelly 2009: Tedesco, 2011) to map daily snow cover and SWE 125 globally. These products have been described in great detail elsewhere therefore only 126 a brief description will be provided here. 


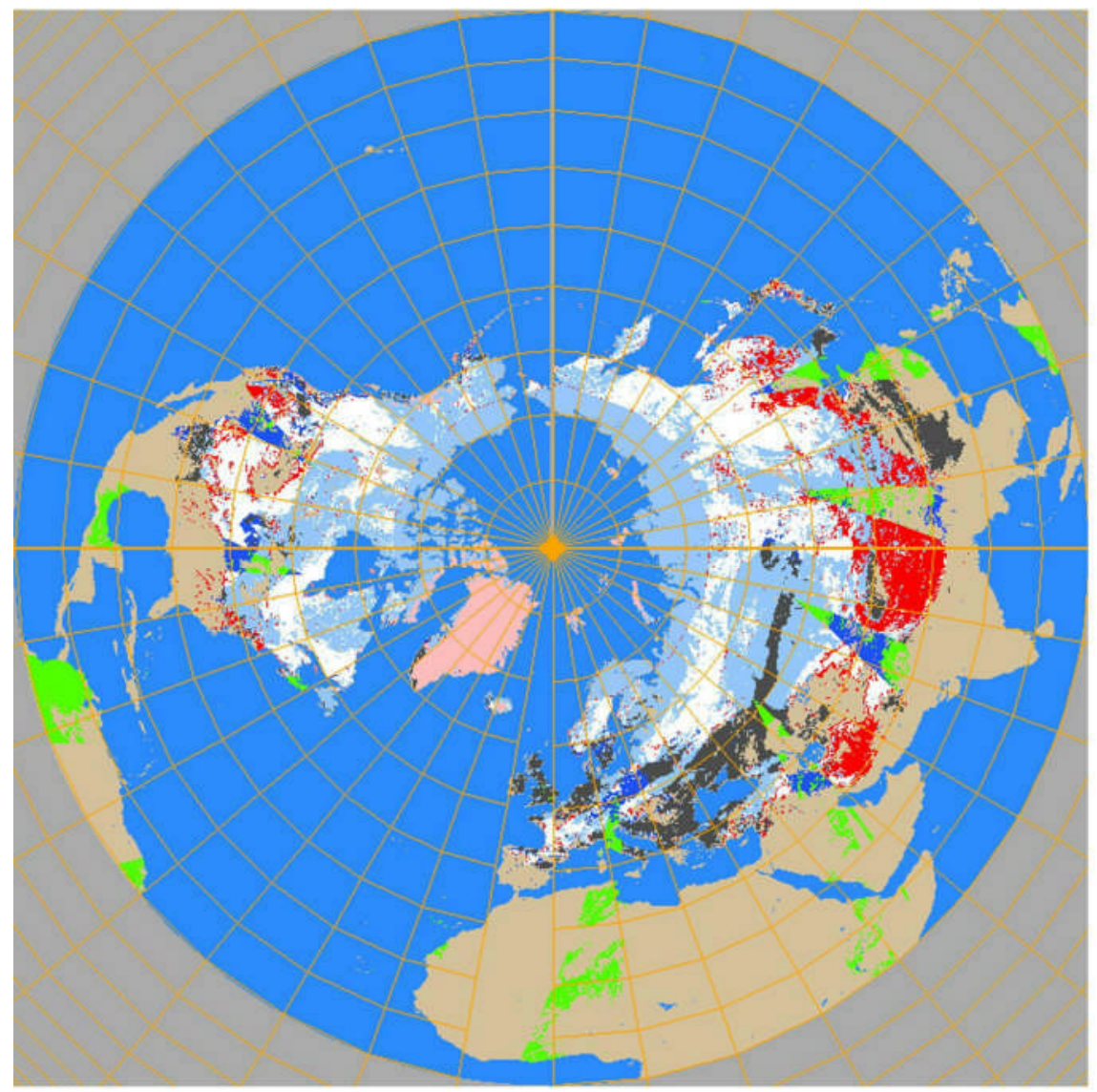

Snow by both sensors

Snow by AMSR_E, MODIS cloud or no data

Snow by MODIS, AMSR_E no snow or orbit gap

No snow by MODIS or AMSR_E but cloud obscured

No snow: no snow by MODIS in clear view but, AMSR_E detects snow

Cloud by MODIS in AMSR_E orbit gap

Snow free land by both MODIS and AMSR_E

\section{Figure 2}

130 MODIS standard snow maps (MOD10C1) provide high-quality, daily and global snow-

131 cover maps at a spatial resolution of up to 500 m (Hall et al., 2002; Riggs et al., 2006).

132 A 500-m resolution MODIS snow-cover map is shown in Figure 1b, however, in the

133 ANSA product, we use 5-km resolution snow products as the default for mapping snow 
134 cover. AMSR-E data can map snow through clouds and darkness and provide

135 estimates of SWE at a spatial resolution of $\sim 25 \mathrm{~km}$. AMSR-E-derived snow cover is

136 used when clouds preclude MODIS from providing a snow map.

138 SWE derived from the ANSA product comes only from the AMSR-E. The MODIS VNIR

139 bands cannot directly measure snow depth, nor can they image through cloud cover

140 which is persistent in the Lower Great Lakes region during the wintertime.

142 Previous work (Figure 3) has shown that use of the ANSA product enables improved

143 mapping of snow-cover extent in the Lower Great Lakes region relative to using either

144 MODIS or AMSR-E maps alone (Hall et al., 2009). Use of the ANSA snow products

145 was also found to improve the mapping of snow-cover extent for the 2007-08 winter in a

146 mountainous area in the eastern part of Turkey where the elevation ranges between

147850 and $3000 \mathrm{~m}$ (Akyurek et al., 2010). 91\% agreement was obtained between the

148 ANSA snow maps and in-situ observations for February 2008. This is the first time that

149 the ANSA snow cover product was evaluated in a mountainous area. Daily snow data

150 collected at 36 meteorological stations were used for validation. 


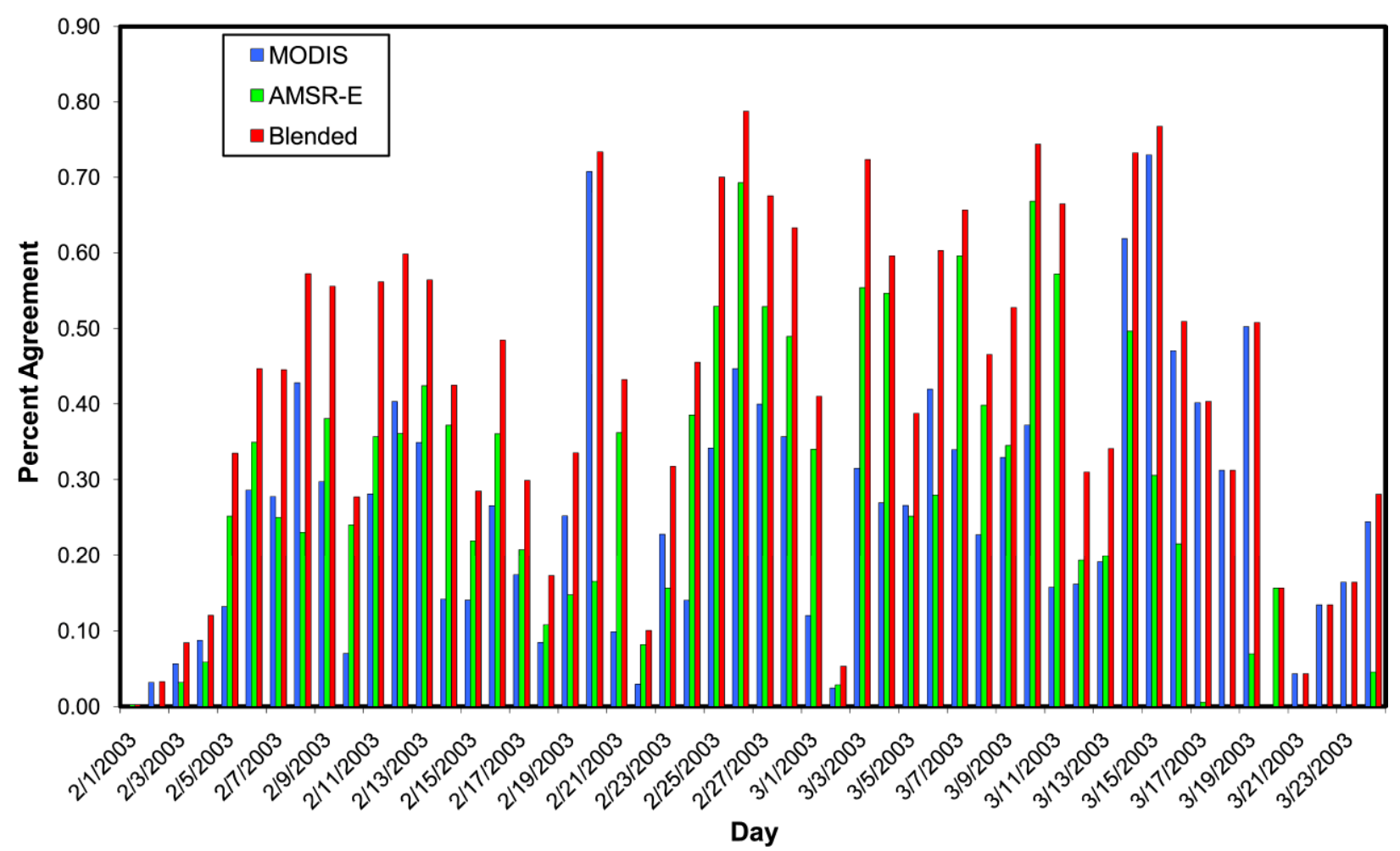

Figure 3

156 Methodology

158 We use National Climatic Data Center (NCDC) co-op station data (Figure 4) for the five

159 winters from 2005-06 through 2009-10 in the Lower Great Lakes region, to compare

160 with ANSA-derived SWE (Figure 4). Co-op snow depth data were interpolated to

161 develop a daily map (see a sample of an interpolated map for 1 December 2007, in

162 Figure 5) and then converted to SWE using two different density conversion factors: 0.2

163 and 0.3 (representing snow densities of 0.2 and $0.3 \mathrm{~g} / \mathrm{cm}^{3}$, respectively). Since the

164 exact snow density was unknown (snow density is not routinely made at co-op stations),

165 initially, we converted snow depth to SWE using the above snow densities, which are 
166 reasonable for the conditions and time of year. (In reality the snow density changes

167 over time as the snow metamorphoses.)

168

169

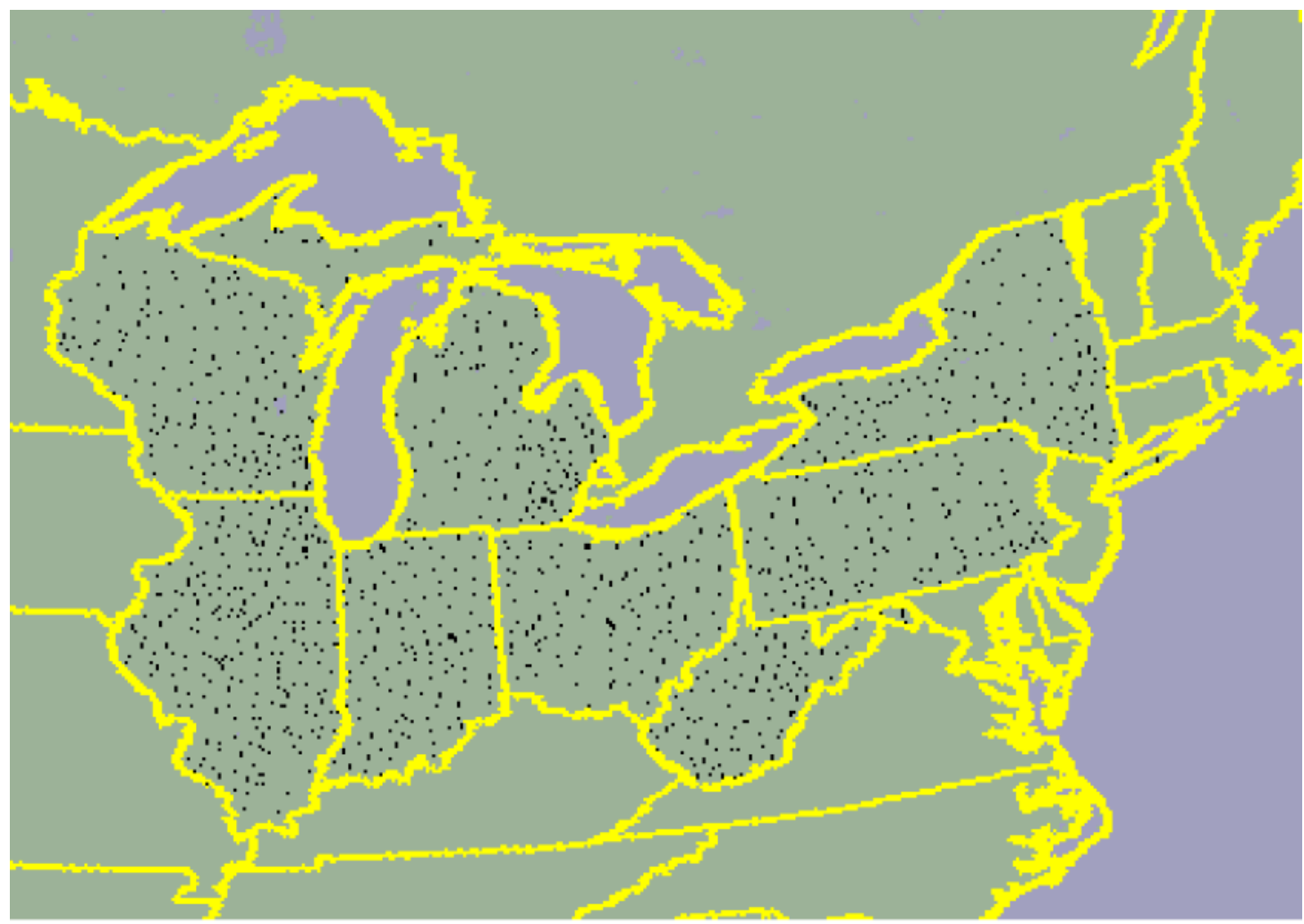

Figure 4

170 

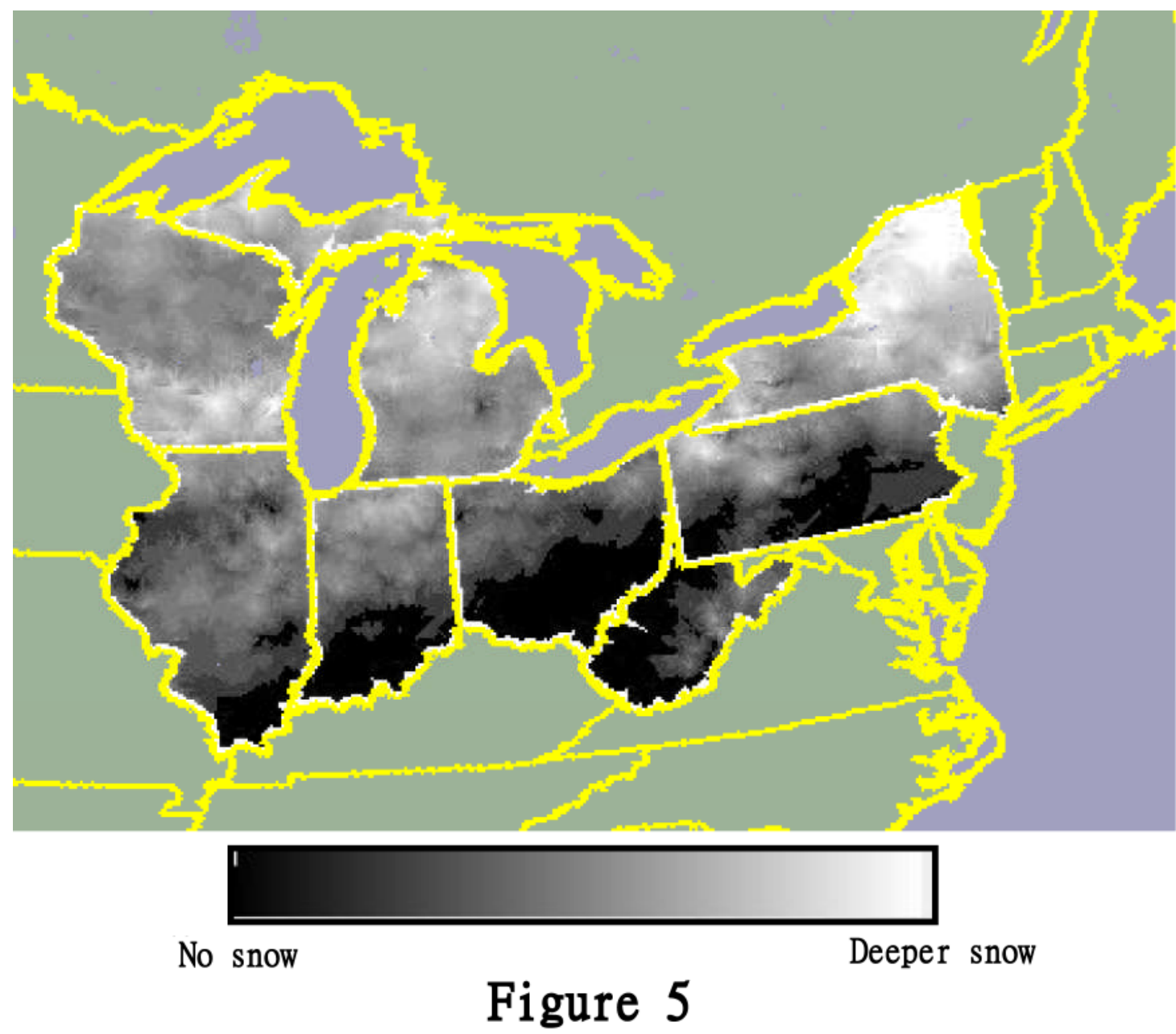

173 Daily difference maps were then constructed to evaluate the accuracy of ANSA-derived

174 SWE as compared with SWE derived from interpolated station data. These difference

175 maps (ANSA SWE minus station-derived SWE) can be considered a measure of

176 deviation (or error) of the ANSA SWE from the "truth," the co-op station data. The

177 RMSE quantifies an over- or under-estimate of the actual SWE. RMSE was calculated

178 for each pixel for each day's snow map. RMSE was averaged to get a daily value for

179 the entire region of interest (or domain). 
181 We then developed two methods to bias correct the ANSA daily SWE maps. The 182 attributes of each method are described below.

184 First, a monthly error was determined by calculating the mean difference of ANSA SWE 185 minus station-derived SWE for each cell for each day of each month (November, 186 December, January, February and March of each year). This calculation was repeated 187 for each of the five winters, 2005-06 through 2009-10, resulting in a 5-year bias map for 188 each month. To remove the 5-year bias from each daily ANSA map, the mean-monthly 189 difference was subtracted from the ANSA SWE in each cell; this produced bias190 corrected SWE maps for each day of each month studied.

192 Second, a 7-day running mean (7DRM) using days immediately before the day of

193 interest was calculated and the average difference map of those seven days was used 194 as a bias to correct the ANSA SWE data on the following day. For example, the 7-day 195 period, 1-7 January, is used to calculate the 7DRM to bias correct the ANSA SWE on 196 the 8 January snow map, then a correction would be calculated for 2-8 January, from 197 which a new bias is used to correct the 9 January map, and so on. The daily RMSE, 198 the difference between the ANSA data corrected with the 7DRM method, and the 199 corresponding station data, is computed each day. 
204 The difference between the SWE derived from the interpolated co-op data compared to

205 the ANSA-derived SWE for each cell without any bias correction is shown in Figures 6a

206 and 6b. The blue colors indicate where the ANSA map underestimates SWE as

207 compared to station data, and the pink colors indicate that ANSA overestimates SWE.

208 The areas of best agreement are shown in neutral colors.

209

210

Jan. 2008
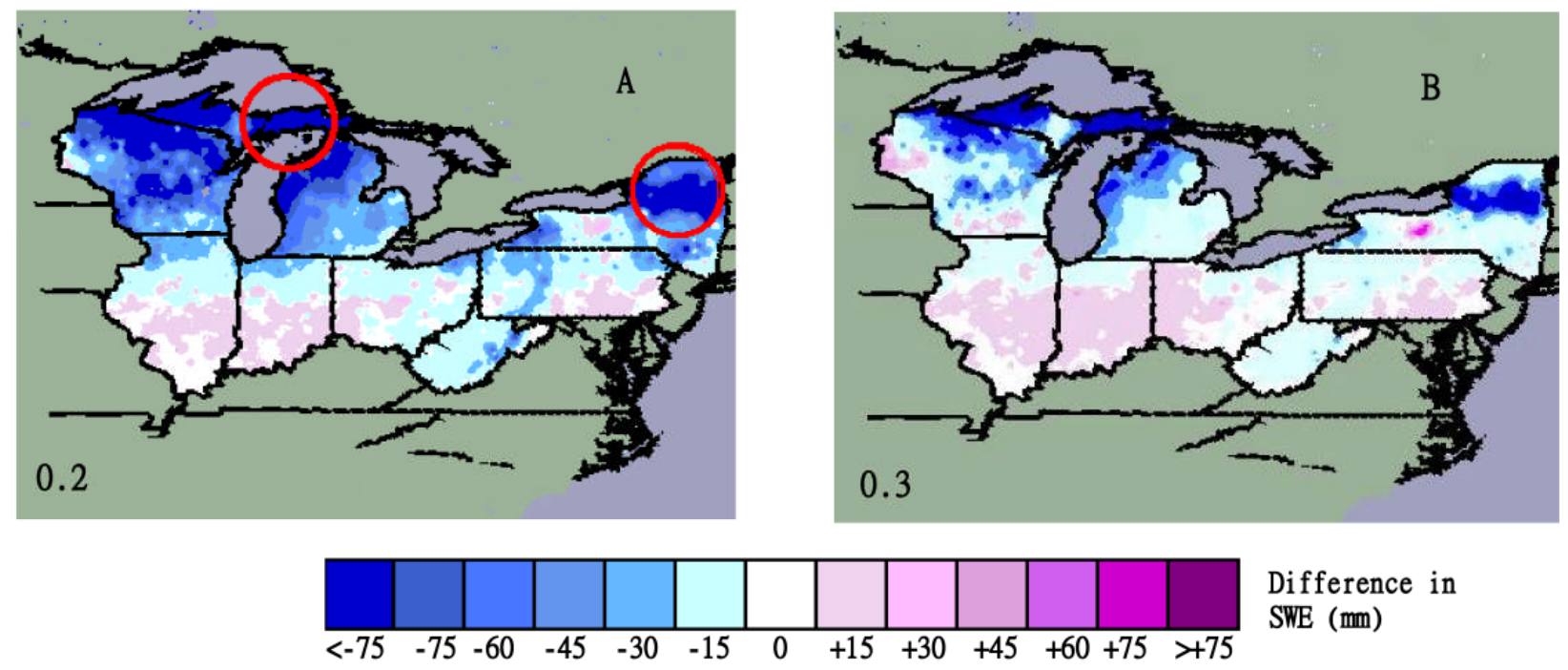

Difference in

SWE (mm)

Feb. 2008
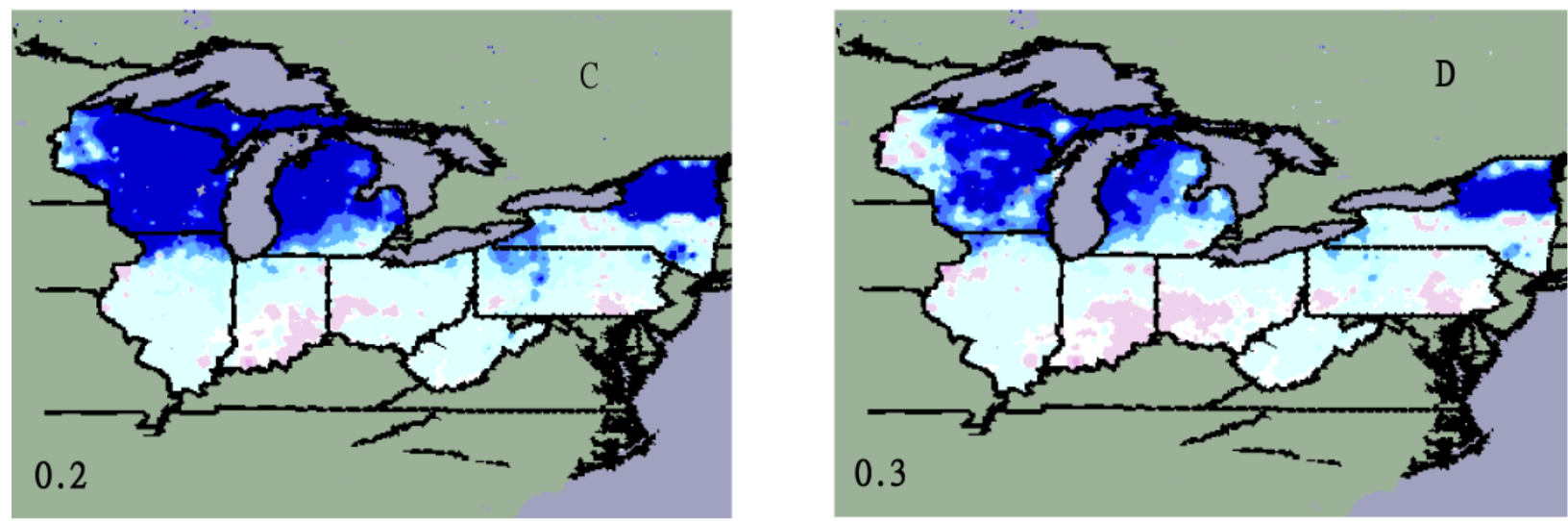
213 In January and February of 2008, ANSA underestimates SWE in densely-forested areas

214 such as in the Upper Peninsula of Michigan and in the Adirondacks in New York State

215 by up to $\sim 75 \mathrm{~mm}$ (see red circles in Figure 6a). Even when using its forest-fraction

216 adjustments (Foster et al., 2005), passive-microwave algorithms still underestimate

217 SWE in dense forests.

219 Conversion of snow density to SWE. What snow density should be used to convert 220 the co-op snow depths to SWE? Ideally the snow density should vary as described in

221 Foster et al. (2005). However, lacking specific information on snow-cover

222 metamorphism in this study area, we decided to use a fixed snow density to compute

223 the snow depth from the AMSR-E SWE measurements. In both the January and

224 February 2008 difference maps (Figures 6a \& b), there is overall better agreement when

225 a snow density of $0.3 \mathrm{~g} / \mathrm{cm}^{3}$ was used to convert the snow depths to SWE versus using

$2260.2 \mathrm{~g} / \mathrm{cm}^{3}$ (Figures $6 \mathrm{c} \& \mathrm{~d}$ ). Note the substantial differences when different snow

227 densities are used to convert snow depth to SWE. This demonstrates the need to

228 improve density estimates, especially in areas where snow conditions change rapidly,

229 and to incorporate dynamic features into SWE algorithm so that the density changes

230 with time.

233 Improvement of ANSA SWE calculation using bias correction. There are both 234 systematic (bias) and random errors associated with the passive-microwave 
235 measurements. In order for the remotely sensed SWE observations to be useful for

236 climate modelers, for instance, it is necessary to have both an unbiased SWE estimate

237 and a quantitative, rather than qualitative, estimate of the uncertainty (random errors).

238 This is a critical requirement for successful assimilation of snow observations into land 239 surface models.

241 First, we experimented with the 5-year bias information to produce "5-year bias-

242 corrected" SWE maps as shown in Figure 7a. Only areas that are currently snow

243 covered are displayed on the maps, and non-snow-covered terrain is shown in green.

244 Using the 5-year bias correction, the RMSE improves on most days in most months.

245 However when anomalous snow conditions occur, the 5-year bias correction can 246 substantially increase the RMSE.

248 In general, there is considerable improvement in the accuracy of the ANSA SWE 249 measurement as compared to station data, when we remove the 5-yr average bias. 250 This can be seen by comparing Figures $7 \mathrm{a}$ and $7 \mathrm{~b}$, and by noting that the RMS errors 251 are lower when the 5-yr bias is removed as seen in Figure 8. This bias-correction 252 technique works quite well when snow conditions on a given day are reasonably close 253 to "average." However when snow conditions are anomalous, as seen in Figure 9, use 254 of the 5-yr bias correction can result in higher RMSE values (see green line). 255 

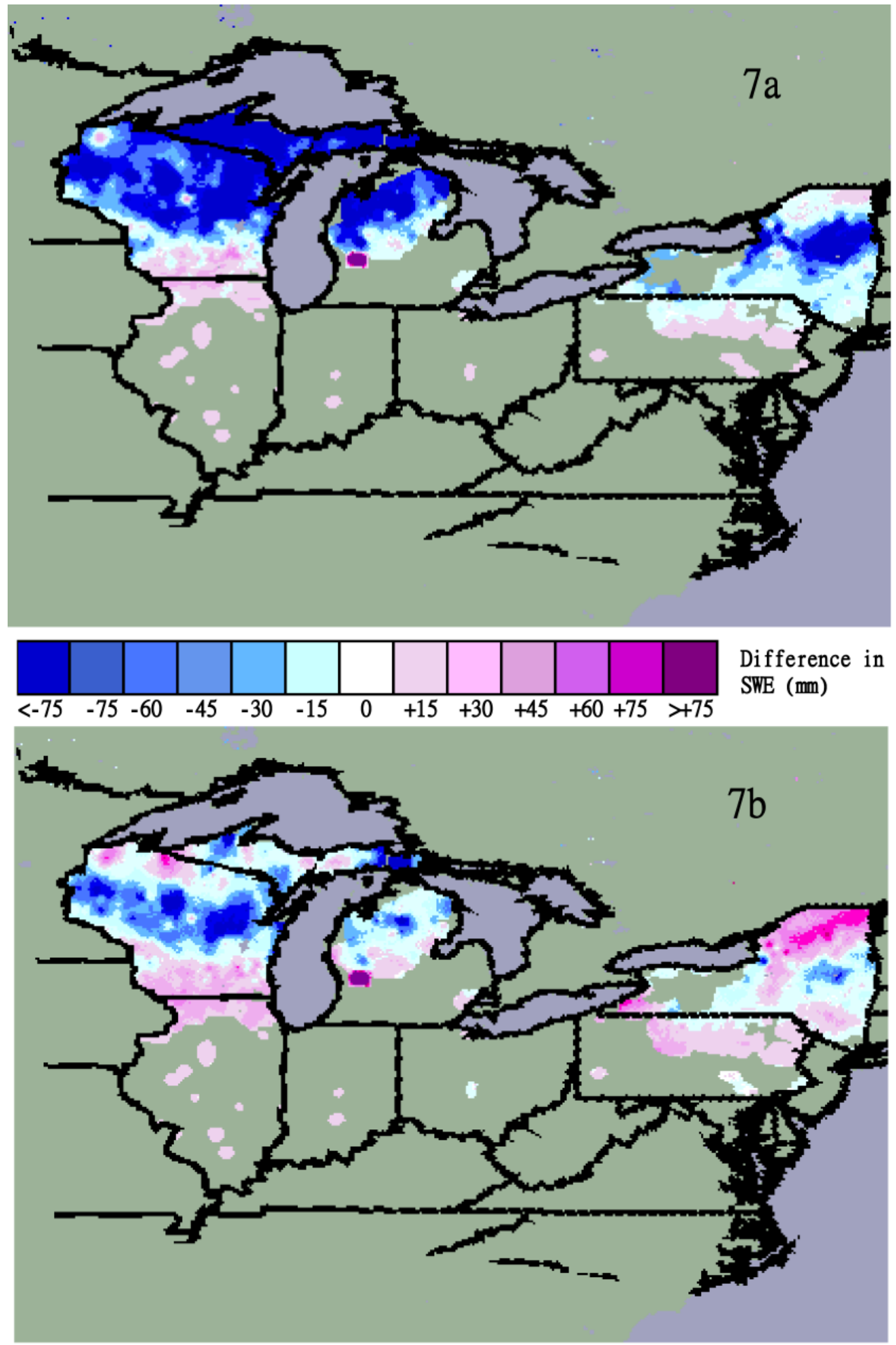


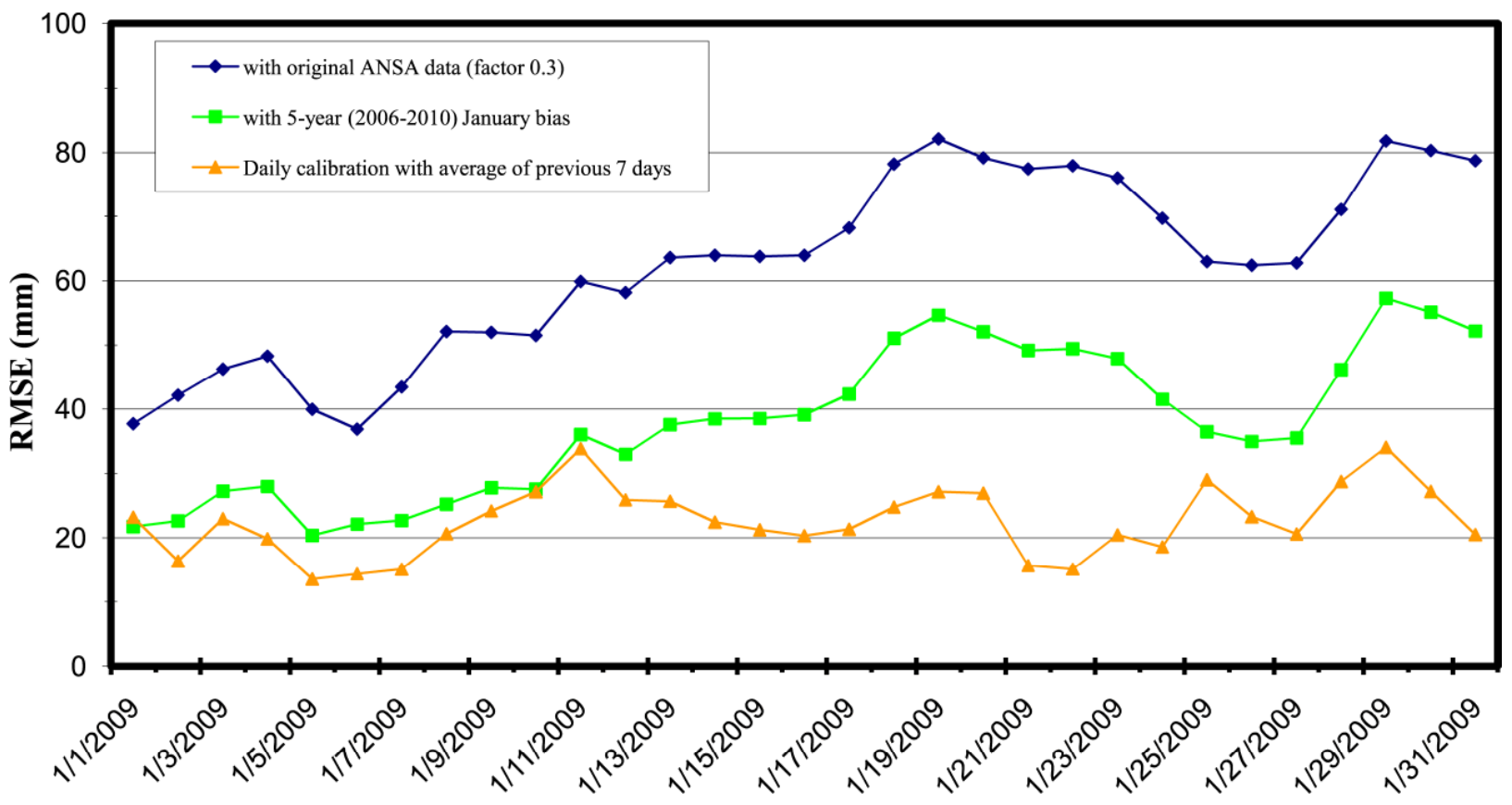

DATE

Figure 8

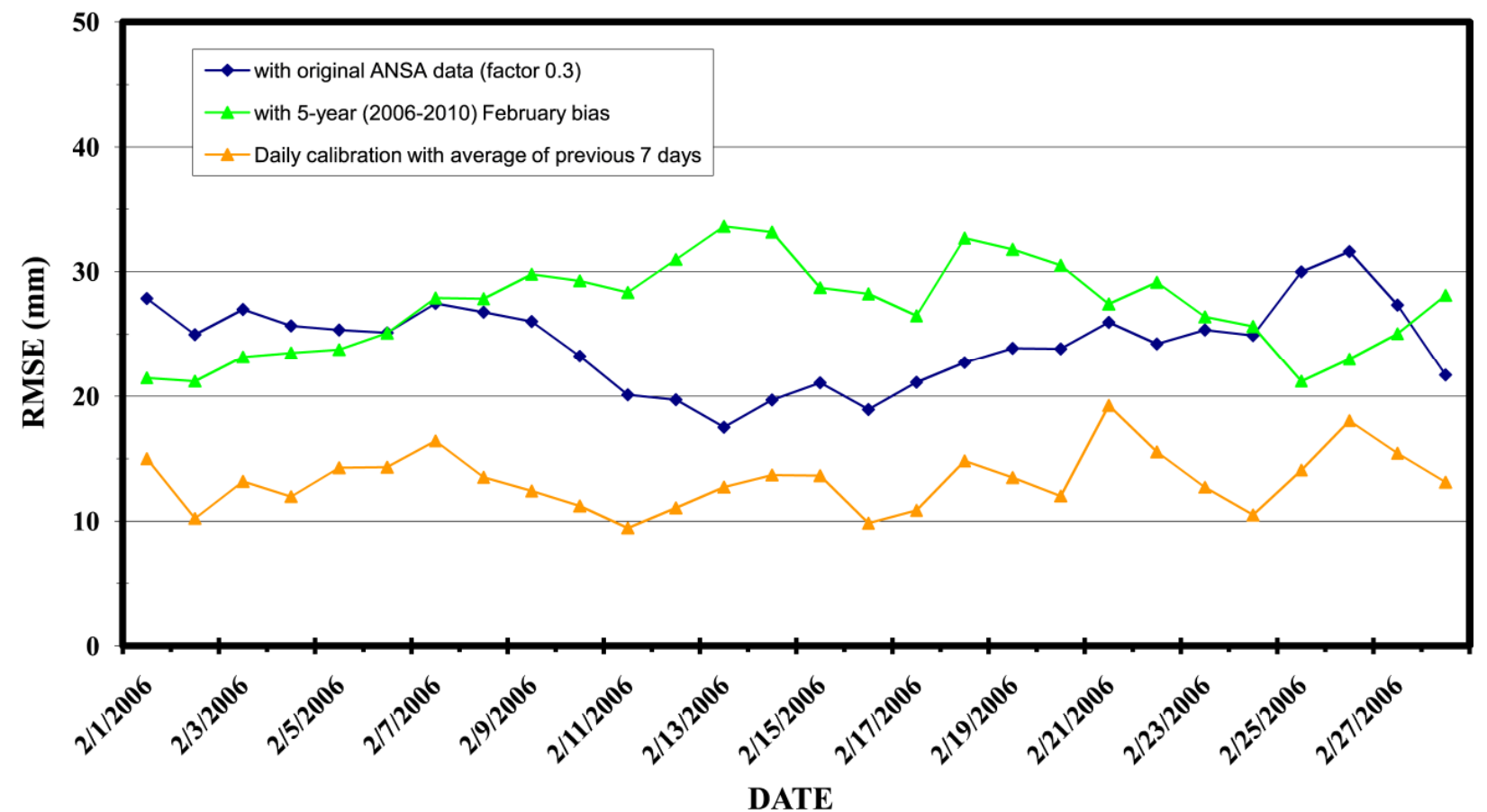

Figure 9 
263 Between 6 and 8 February 2006 we see a change in the RMSE values (Figure 9)

264 because the original ANSA data (with no bias correction) matches the interpolated snow

265 depth map better than does the 5-year bias-corrected data. For most of February 2006,

266 snow conditions differed considerably from the 5-year average and therefore the 5-year

267 bias correction did not offer improvement in this case. For example, in Indianapolis,

268 Indiana, which is representative of the Lower Great Lakes region, the temperatures

269 were warmer than normal in February and the snowfall was much lower than average.

270 Only three days recorded $2.5 \mathrm{~cm}$ of snow on the ground (4-6 February 2006), and

271 there was no day that recorded more than $5 \mathrm{~cm}$ of snow. In addition, there was no snow

272 on the ground (other than a trace) after 6 February.

273 In all cases that we studied during the five winters, the 7DRM bias-correction technique

274 worked better than using either no bias correction for the ANSA SWE data, or using the

275 5-year average bias-correction technique. The 7DRM approach captures the snow

276 conditions just before the day in question. Future work calls for trying additional ways to

277 bias-correct the ANSA data using data just prior to the day in question, but allowing a

278 few days' delay to acquire the data to perform the bias correction.

279 Models that improve the evolution of snowpack parameters, including grain size

280 information, and use of dynamic algorithms that better account for changes in snow

281 density, should be the focus of future work. A dynamic method of calculating snow

282 density in a passive-microwave SWE algorithm would likely result in improved SWE

283 estimates from microwave sensors. 
286 Conclusions

288 We have examined the ability of the ANSA blended-snow product to measure SWE in 289 the Lower Great Lakes region of the U.S. The ANSA product underestimates SWE in 290 dense forests. This is a known limitation of passive-microwave SWE algorithms. Thus 291 we employed bias-correction methods to reduce the errors when measuring SWE from 292 ANSA. First, we calculated the 5-year mean-monthly bias (difference between co-op293 derived SWE and AMSR-E SWE) from the daily maps from each month (November 294 through March) of each winter from 2005-06 to 2009-10. Those values, on a cell-by-cell 295 basis, were subtracted from the ANSA SWE values for each day of each corresponding 296 month. Results show an improvement in agreement between the co-op station-derived 297 and ANSA SWE after the monthly bias was removed.

299 Estimation of snow density is needed to convert the co-op station snow depths to SWE 300 values, so that ANSA SWE can be compared with "ground truth." For our study area, 301 use of a conversion factor of 0.3 (corresponding to a snow density $=0.3 \mathrm{~g} / \mathrm{cm}^{3}$ ) provides 302 overall better agreement between ANSA and co-op SWE for both January and February 3032008 , than when we used a snow density of $0.2 \mathrm{~g} / \mathrm{cm}^{3}$.

305 For most of the months during the five-year period, the 5-year bias correction improved 306 the agreement between the ANSA-derived and station-derived SWE. However, 307 anomalous months such as when there was very little snow on the ground compared to 
308 the 5-year mean, or months in which the amount of snow was much greater than the 5-

309 year mean, showed poorer results. We also used the 7DRM bias-correction method

310 using the 7 days just prior to the day in question. As before, we then corrected the

311 ANSA data. This method was more effective in reducing the RMSE between the ANSA-

312 and co-op-derived SWE values, and in capturing the effects of anomalous snow

313 conditions.

314

315

\section{Acknowledgements}

317

318 This work is funded by the U.S. Air Force Weather Agency (AFWA) and NASA's

319 Hydrology Program. Special thanks are due to John Eylander / CRREL, for his support 320 of this work while employed at AFWA. 


\section{References}

323 Akyurek, Z., D.K. Hall, G.A. Riggs and A.U. Sorman, 2010: Evaluating the utility of the

324 ANSA blended snow cover product in the mountains of eastern Turkey, International

325 Journal of Remote Sensing, 31(14):3727-3744.

326

327 Brown, R.D., 2000: Northern Hemisphere snow cover variability and change, 1915-

328 1997, Journal of Climate, 13:2339-2355.

330 Brown, R.D. and D. A. Robinson, 2011: Northern Hemisphere spring snow cover

331 variability and change over 1922-2010 including an assessment of uncertainty, The

332 Cryosphere, 5, 219-229, doi:10.5194/tc-5-219-2011.

333

334 Brown, R.D., B. Brasnett and D. Robinson, 2003: Gridded North American monthly

335 snow depth and snow water equivalent for GCM evaluation, Atmosphere-Ocean, 41:133614.

338 Brown, R., C. Derksen and L. Wang, 2010: A multi-data set analysis of variability and 339 change in Arctic spring snow cover extent, 1967-2008, Geophysical Research Letters, 340 115(D16111):16, doi:10.1029/2010JD013975.

341 Foster, J., C. Sun, J. Walker, R. Kelly, A. Chang, J. Dong, and H. Powell, 2005:

342 Quantifying the uncertainty in passive microwave snow water equivalent observations,

343 Remote Sensing of Environment, 94:187-203. 
345 Foster, J.L., D.K. Hall, J.B. Eylander, G.A. Riggs, S.V. Nghiem, M. Tedesco, E.J. Kim,

346 P.M. Montesano, R.E.J. Kelly, K.A. Casey and B. Choudhury, 2011: A blended global

347 snow product using visible, passive microwave and scatterometer data, International

348 Journal of Remote Sensing, 32(5):1371-1395. doi.org/10.1080/01431160903548013.

350 Frei, A., M. Tedesco, S. Lee, J.L. Foster, D.K. Hall, R.E.J. Kelly and D.A. Robinson,

351 submitted: A review of current-generation satellite-based snow products, Advances in

352 Space Research.

353

354 Hall, D.K. and G.A. Riggs, 2007: Accuracy assessment of the MODIS snow-cover

355 products, Hydrological Processes, 21(12):1534-1547, doi:10.1002/hyp.6715.

357 Hall, D.K., G.A. Riggs, V.V. Salomonson, N.E. DiGirolamo and K.A. Bayr, 2002: MODIS 358 snow-cover products, Remote Sensing of Environment, 83:181-194.

360 Hall, D.K., J.L. Foster, G.A. Riggs, R.E.J. Kelly, J.Y.L. Chien and P. Montesano, 2009:

361 Preliminary evaluation of the AFWA-NASA (ANSA) blended snow-cover product,

362 Proceedings of the 66th Eastern Snow Conference, xxxx - xxxx June 2009, Niagara-on-

363 the-Lake, Ontario, Canada, pp.27-34. 
365 Helfrich, S.R., D. McNamara, B.H. Ramsay, T. Baldwin and T. Kasheta, 2007:

366 Enhancements to, and forthcoming developments in the Interactive Multisensor Snow 367 and Ice Mapping System (IMS), Hydrological Processes, 21:1576-1586.

369 Kelly, R.E.J., 2009: The AMSR-E Snow Depth Algorithm: Description and Initial Results, 370 Japanese Journal of Remote Sensing, 29(1): 307-317, (GLI/AMSR Special Issue).

372 Kelly, R.E.J., A.T.C Chang, J.L. Foster, and M. Tedesco, 2004, updated daily). AMSR-

373 E/Aqua Daily L3 Global Snow Water Equivalent EASE-Grids V002. Boulder, Colorado

374 USA: National Snow and Ice Data Center. Digital

375 media.http://nsidc.org/data/ae_dysno.html

376

377 Ramsay, B., 1998: The interactive multisensory snow and ice mapping system, 378 Hydrological Processes, 12:1537-1546.

380 Riggs, G.A., Hall, D.K. and Salomonson, V.V., 2006: MODIS Snow Products User

381 Guide, http://modis-snow-ice.gsfc.nasa.gov/sugkc2.html .

383 Robinson, D.A., K.F. Dewey and R.R. Heim, 2003: Global snow cover monitoring: an 384 update, Bulletin of the American Meteorological Society, 74:1689-1696.

386 Tedesco, M., R. E. J. Kelly, J. L. Foster and A. T. C. Chang (2011 updated daily).

387 AMSR-E/Aqua Daily L3 Global Snow Water Equivalent EASE-Grids V002, National 
388 Snow and Ice Data Center Digital Media, Boulder Colorado, USA, Digital media, 389 http://nsidc.org/data/ae dysno.html 
Figure captions

392 Figure 1a. Terra MODIS image acquired on 16 February 2008 showing snow cover in

393 the vicinity of the Great Lakes in the northern United States and southern Canada.

394 There is ice cover on Lake Erie but the other Great Lakes are mainly cloud covered.

395 Image courtesy of the Earth Observatory Image of the Day

396 http://earthobservatory.nasa.gov/IOTD/view.php?id=8485. Figure 1b. MODIS snow-

397 cover fraction (SCF) map of the same area shown in Figure 1a.

399 Figure 2. ANSA blended-snow product for 26 January 2007 in Lambert Azimuthal polar 400 projection (Foster et al., 2011).

402 Figure 3. Relationship of the Percent of Agreement of the ANSA product, and the

403 MODIS and AMSR-E input products, alone, as compared to meteorological station data 404 for the lower Great Lakes region for mapping snow-cover extent in 2003. The AMSR-E 405 contribution (green) becomes more important in late February during periods of

406 cloudiness when MODIS cannot map the snow (after Hall et al., 2009).

408 Figure 4. Dots represent locations of NCDC co-op stations used in this study. 409

410 Figure 5. 1 Dec. 2007 snow depth map interpolated from co-op station measurements.

411 Snow depths are shown in various shades of black and white (lighter grey indicates 412 deeper snow). 
414 Figure 6. Mean difference between ANSA and station-derived SWE for January (A \& B)

415 and February 2008 (C \& D) using 0.2 conversion factor ( $A$ \& C), and 0.3 conversion

416 factor (B \& D). Conversion factors are used to convert co-op station snow-depths to

417 SWE and are based on snow density. The blue colors indicate where the ANSA map

418 underestimates SWE as compared to station data, and the pink colors indicate that

419 ANSA overestimates SWE.

421 Figure 7a. Mean difference between ANSA and station-derived SWE for 2 January

422 2009. Figure 7b. Mean difference between ANSA and station-derived SWE for 2

423 January 2009, but in this image, the 5-year bias was subtracted from the result in Fig.

$4247 a$, for each cell. In these images, the non-snow-covered land areas are shown in 425 green.

427 Figure 8. Plot of the RMSE for January 2009. The top (blue) line corresponds to Figure $4287 \mathrm{a}$ (no bias correction), and the green line corresponds to Figure 7b (5-year bias 429 correction method). The orange line represents results using the 7-day running mean 430 (7DRM) bias-correction method.

432 Figure 9. Plots of the RMSE for the month of February 2006. The blue line represents 433 the case where the original ANSA data were compared with the station-derived SWE 434 (no bias correction), and the green line represents the case where the 5-yr bias 435 correction was used. Note in the middle of the month that the errors are greater when 
436 the 5-yr bias correction is used. The orange line represents results using the 7-day

437 running mean (7DRM) bias-correction method.

438

439

440

441

442

443 